Int. J. Electrochem. Sci., 11 (2016) $6735-6746$

International Journal of

ELECTROCHEMICAL

SCIENCE

WWw.electrochemsci.org

\title{
Synergistic Electronic Pull of Graphene Oxide Supported Pd Nanoparticles on Enhancing Catalytic Activity of Electro Deposited Pt Nanoparticles for Methanol Oxidation Reaction
}

\author{
Ammar Bin Yousaf ${ }^{1, \S, *}$, Rashid Khan ${ }^{2,}$, Muhammad Imran ${ }^{1}$, Carlos Fernandez ${ }^{3}$, Cheng-Zong Yuan ${ }^{1}$ \\ and Li Song ${ }^{2}$ \\ ${ }^{1}$ Hefei National Laboratory for Physical Sciences at Microscale, School of Chemistry and Material \\ Sciences, University of Science and Technology of China, Hefei 230026, P. R. China \\ ${ }^{2}$ National Synchrotron Radiation Laboratory, CAS Canter for Excellence in Nanoscience, University \\ of Science and Technology of China, Hefei 230029, P. R. China \\ ${ }^{3}$ School of Pharmacy and Life Sciences, Sir Ian Wood Building, Robert Gordon University, AB10 \\ 7GJ Aberdeen, UK \\ ${ }^{\S}$ These two authors contributed equally to this work \\ *E-mail: ammar@mail.ustc.edu.cn
}

doi: $10.20964 / 2016.08 .12$

Received: 25 April 2016 / Accepted: 29 May 2016 / Published: 7 July 2016

Graphene oxide supported clean Pd nanoparticles were synthesized by using $\mathrm{CO}$ as a reducing agent. Pt film was deposited on Pd NPs through electrochemical potential cycling method. The as-developed catalyst, which exhibits higher catalytic performance for electro oxidation of methanol and better tolerance to the $\mathrm{CO}$ poisoning effect suffered during methanol oxidation reaction (MOR). The higher performance of catalyst attribute towards the long chain organic capping agent free formation process of clean PdPt nanocomposite. This facile and effective route is of great significance for the synthesis of Pd-based catalysts on electrode surface directly with highest MOR activity. The synergistic electronic pull provided by graphene oxide supported Pd nanoparticles to Pt in the composite material highly enhanced the electro catalytic activity.

Keywords: Pd Nanoparticles, Pd-Pt Nanocomposite, graphene oxide support, electrochemical deposition, synergistic effect, methanol oxidation reaction

\section{FULLTEXT}

(C) 2016 The Authors. Published by ESG (www.electrochemsci.org). This article is an open access article distributed under the terms and conditions of the Creative Commons Attribution license (http://creativecommons.org/licenses/by/4.0/). 